\title{
Serviços Públicos
}

\section{CONCESSÃO DE SERVIÇO PORTUÁRIO - ADJUDICAÇÃO DIRETA - DISPENSA DE LICITAÇÃO}

\section{- Concessão e autorização.}

- Concessão de porto. Legislação. Teoria da recepção.

- Pessoa de direito público. Dispensa de licitação.

\section{PARECER}

\section{I}

O estado do Espírito Santo foi titular de concessão para explorar o porto de Vitória até o advento do Decreto $n^{\circ} 82.279$, de 18 de setembro de 1978, com o qual foi encampado o serviço, ficando os bens e instalações sob guarda e gestão da Portobrás. A seguir, foi a exploração do porto outorgada a sociedade de economia mista, sob controle acionário da Portobrás, a qual se transformou na Companhia Docas do Espírito Santo (Codesa), conforme Decreto ${ }^{\circ} 87.560$. de 9 de setembro de 1982.

A Lei $n^{\circ} 8.029$, de 12 de abril de 1991, autorizou o Poder Executivo a promover a dissolução da Portobrás, cabendo à União Federal sucedê-la em seus direitos e obrigações.

Em Assembléia Geral de liquidação da Portobrás, em vias de realização, a União Federal retomará a execução do serviço relativo ao porto de Vitória, cogitando-se de possibilidade de que Estado do Espírito Santo, diretamente ou por meio de empresa sob seu controle, volte a assumir a exploração comercial do porto.

A consulta que nos foi formulado, considerando a expectativa dessa transferência, indaga:

a) se a relação jurídica a se constituir entre a União Federal e o estado do Espírito Santo corresponde a concessão, permissão ou autorização;

b) se a atribuição do serviço ao estado do Espírito Santo dependerá de prévia licitação, tendo-se em vista o disposto no art. $175 \mathrm{da}$ Constituição Federal.

\section{II}

A resposta aos quesitos da consulta pressupõe a definição de premissas essenciais ao entendimento da matéria.

De início importa distinguir conceitos, não raro confundidos, porém diversos em seu conteúdo.

A autorização é ato administrativo que corresponde ao exercício, pela Administração, do poder de polícia mediante o qual e em função do interesse público a autoridade faculta ao particular a prática de uma atividade que lhe é própria, embora diferida em sua eficácia.

A autorização não é ato atributivo do direito. Representa ato liberatório pelo qual a Administração permite que a potencialidade de um direito ou liberdade individual se torne concreta. A eficácia contida adquire plenitude, uma vez concedida a autorização.

A autorização, em suma, não cria direito novo. Antes liberta direito preexistente. $\mathrm{O}$ ti- 
tular é legítimo senhor de um direito, mas não dispõe da faculdade de exercê-lo, até que seja autorizado.

Como excelentemente definido na doutrina italiana, a autorização é ato que remove obstáculo ou limite oposto à efetiva fruição de um direito individual.

Na palavra de Aldo Sandulli, consiste essencialmente em:

"Rimuovere un limite all'esercizio di un potere" (Il procedimento amministrativo, 1959 , p. 67).

Ou, como adverte Renato Alessi:

"Conferisce semplicemente al privato la giuridica potestà di esercizio de un diritto del quale per l'addietro il privato stesso era già titulare, rimovendo gli ostacoli e i ilimiti giuridici poste della legge all'esercizio diritto stesso in difetto di autorizzacione" (Sistema Istituzionale del Diritto Amministrativo Italiano, 1953. p. 390).

Vignocchi aponta na autorização a figura de um ato de controle preventivo que se caracteriza pelo condicionamento de uma situação jurídica preexistente (La natura giuridica dell'autorizzacione amministrativa, 1944, p. 107).

Ranelletti, em obra de 1894, examinando os atos administrativos que permitem a ação do particular, proclama que:

"In tutti i casi però questi atti debbono apparire come vere remozione di limiti, che la legge há posti al libero esplicamento dell'attività individuale per razioni di ordine pubblico" (Teoria generale delle autorizzazioni $e$ concezioni admministrativa, 1894, p. 21).

$\mathrm{E}$, confirmando o entendimento, remova o conceito, em obra de 1945:

"In tutti i casi indicati la legge, a tutela dell'interesse pubblico e talora anche dei terzi, vieta al soggetto l'esercizio di un diritto nel compimento di un atto o di un attività o l'acqisito di un diritto, fino a che non ne abbia ottenuto il permesso (autorizzazione) dell'autorità amministrativa.

Questa, perciò, concedendo l'autori $\_$¿azio ne, rimuove il limite che le legge ha posto condizionatamente all'esercizio o all'acquieto del dirritto" (Teoria degli atti amministrativa speciali, $7^{\mathrm{a}}$ edição, 1945, p. 21-2 - grifos do original).

Marcelo Caetano, qualificando como atos administrativos permissivos os que facultam ou permitem a alguém a adoção de uma conduta que em princípio lhe está vedada, coloca, na categoria, as autorizações, assim definidas:

"Em sentido rigoroso, a autorização é o ato administrativo que permite a alguém o exercício de um seu direito ou de poderes legais. A entidade autorizada possui, pois, um direito ou certo poder, mas o exercício deles está-lhe vedado antes que intervenha previamente o consentimento da Administração fundado na apreciação das circunstâncias de interesse público que possam tornar conveniente ou inconveniente esse exercício" (Manual de Direito Administrativo, Forense, $1^{\text {a }}$ edição brasileira, 1970, tomo I, p. 417).

No tocante aos serviços portuários, inexiste direito individual ou domínio privado que possa adquirir vitalidade como efeito de ação administrativa que venha a liberar sua eficácia.

Os portos marítimos se situam em terrenos de marinha, bens públicos federais (Constituição, art. $20, n^{\circ}$ VII), e à União compete sua exploração direta ou delegada (art. $21, \mathrm{n}^{\circ} \mathrm{XII}$, alínea $f$.

A exploração dos portos e, em última análise, um serviço público e, como tal, e não, exercê-lo diretamente, o Poder Público poderá conceder a terceiro o desempenho da atividade.

A situação jurídica nascente é fruto de ato bilateral, relação contratual que se configura como concessão de serviço público.

A concessão, como contrato administrativo, importa delegação ao concessionário dos poderes e deveres de prestação de serviço público específico, reservando-se à Administração concedente a regulamentação a fiscalização do serviço concedido e a reversibilidade dos bem vinculados, quando extinta a concessão, de modo a garantir a continuidade do serviço.

Instituto afim, porém distinto, a permissão é ato unilateral, discricionário e precário, que outorga ao particular a "execução de serviços de interesse coletivo ou o uso especial de bens públicos", na expressão do Hely Loped Mei- 
relles (Direito Administrativo Brasileiro, 15" edição, 1990, p. 165).

A permissão tem a forma de ato autorizativo e obedece a regime jurídico próprio que investe o permissionário na qualidade de leitor de um serviço coletivo.

Daí dizer Miguel Reale que "a permissão se constitui como se fora autorização e é exercida como se fora concessão" (Direito Administrativo - Estudos e pareceres, 1969, p. 1.566).

A permissão é, em suma, mais do que a autorização e menos do que a concessão. Tem como atributos "a unilateralidade, a discricionariedade e a precariedade" (Hely, ob. cit., p. 347).

No que pertine ao serviço público dos portos, a delegação para explorá-lo terá necessariamente a via da concessão, não se compadecendo com sua essência as figuras de autorização ou de permissão.

A promíscua referência no item XII do art. 21 da Constituição às três espécies institucionais deixa ao intérprete precisar a pertinência de cada qual delas com respeito às modalidades do serviço descritos nas várias últimas em que se desdobra o preceito.

\section{III}

A legislação que, no Império, regulava o regime de docas (Lei $n^{\circ} 1.740$, de 13 de outubro de 1869 e Lei $n^{\circ} 3.314$, de 16 de outubro de 1856) sucedeu-se o Decreto $n^{\circ} 24.559$, de 6 de julho de 1934 , que autorizou a concessão de obras e melhoramentos dos portos nacionais.

Emitido pelo Chefe do Governo Provisório, no uso das atribuições conferidas pelo art. $1^{\circ}$ do Decreto $\mathrm{n}^{\circ} 19.398$, de 11 de novembro de 1930, é ato materialmente legislativo. No recesso do Congresso Nacional, confundiam-se, então, na pessoa do Presidente da República, tanto a função executiva como a função legislativa.

Os atos por ele baixados, embora de numeração sucessiva, se distinguiam pela natureza intrínseca, como atos com força de lei (lei materiais) ou atos de caráter regulamentar (atos executivos).
A distinção se afirmará, em cada caso, ratione materiae, segundo a substância do ato.

No tocante ao citado Decreto $\mathrm{n}^{\circ} \mathbf{2 4 . 5 9 9}$, de 1934 , sua natureza jurídica, de teor legislativo, se fixará com a hierarquia de lei, somente passível de ser alterada ou revogada por outra lei.

Mediante Decreto de 15 de fevereiro de 1991 (publicado em Suplemento ao Diário Oficial do 18 do mesmo mês e ano), o Presidente da República declarou revogadas algumas centenas de atos formalmente baixados como decretos, no período entre novembro de 1889 e dezembro de 1990.

Entre os atos ali relacionados figura o referido Decreto ${ }^{\circ} 24.399$, de 6 de julho de 1934.

Todavia, a revogação é inconstitucional e, por via de consequiência, inoperante - pela circunstância elementar de que, tratando-se, como assinalado, de ato materialmente legislativo, não cabe sua revogação por força do decreto executivo.

Acaba, aliás, o Poder Executivo de reconhecer a impropriedade da revogação, anulando-a em novo ato (Decreto de 29 de novembro corrente, art. $1^{\circ}, n^{\circ}$ III).

Subsiste, assim, válido e eficaz o mencionado diploma legal cujo art. $1^{\circ}$ expressamente define como concessão a relação contratual a se constituir com o Estado em cujo território se situa o porto, ou com entidade privada idônea, atributiva do direito de exploração e ampliação do serviço portuário.

\section{IV}

A Constituição prevê, no referido item XII, alínea $f$, a concessão do serviço do portos marítimos $c$, no art. $22, \mathrm{n}^{\circ} \mathrm{XXVII}$ a competência da União para legislar sobre as normas de contratação a serem observadas pela administração direta e indireta.

A prestação do servi zo público sob regime de concessão será feita, como especifica o art. 175 da Constituição na forma da lei.

A aplicabilidade da norma constitucional está, portanto, vinculada à existência de lei que regule a matéria. 
Quando, porém, a Constituição condiciona a aplicação de seus preceitos à disciplina em lei reguladora, o requisito não se subordina necessariamente à edição de lei nova.

$\mathrm{O}$ ordenamento legal que a antecede tem a sua validade e vigência confirmadas pelo princípio da permanência do direito anterior, o qual, perante o advento de uma nova Constituição, mantém a vitalidade da ordem jurídica existente, salvo se conflitante com a norma superveniente de maior hierarquia, hipótese em que a lei ordinária desaparece por revogação, e não por inconstitucionalidade.

A chamada teoria da recepção, abrigada pela doutrina e a jurisprudência, tem o sentido da conservação das leis anteriores a uma Constituição que não a contrariem. Tais leis são recebidas pelo novo sistema constitucional, que as confirma e ratifica.

A nova Constituição tem, em suma, um duplo e simultâneo efeito. Repele o direito anterior que a ela se opõe, mas ao mesmo tempo mantém, sem solução de continuidade, as leis que com ela se harmonizem.

Manoel Gonçalves Ferreira Filho, em estudo sobre a recepção em direito constitucional, evidencia o equívoco do raciocínio de que a legislação ordinária, editada sob os auspícios de uma Constituição, que lhe serve de fundamento, deverá acompanhar-lhe o perecimento quando essa Constituição é revogada pela promulgação da outra:

"Na verdade o que ocorre sempre - ensina o eminente constitucionalista - é que, salvo incompatibilidade entre a legislação ordinária anterior e as normas de nova Constituição, se considera que essas normas ordinárias anteriores persistem válidas e eficazes". (Enciclopédia Saraiva de Direito, vol. 63. p. 334).

$E$, em abonação da tese, invoca a lição de Kelsen, assim expressa:

"Se as leis emanadas sob a velha Constituição continuam a ser válidas sob a nova, isso é possível somente porque lhe foi conferida validade expressa ou t:citamente pela nova Constituição. O fenômeno é um caso de recepção, similar à recepção do direito romano. O novo ordenamento recebe, i.e., adota certas normas do velho ordenamento. Isso significa que o novo ordenamento atribui validade, dá vigor a normas que tem o mesmo conteúdo das normas do velho ordenamento. A recepção é um processo abreviado de criação do direito" (Teoria generale del Diritto e dello Stato, p. 119).

No caso, adverte Manoel Gonçalves Ferreira Filho, trazendo à colação conceito de Mortati, "ocorre uma novação de fontes".

No mesmo sentido é o pensamento de Jorge Miranda (Manual de Direito Constitucional - tomo II, p. 244-45):

"A subsistência de quaisquer normas ordinárias anteriores à nova Constituição depende de um único requisito: que não sejam desconformes com ela. Se forem desconformes, só poderão, eventualmente, sobreviver se elevadas elas próprias então à categoria de normas constitucionais, quer dizer, se constitucionalizadas.

Por isso, o único juízo a estabelecer é o juízo da conformidade (ou da compatibilidade) material com a nova Constituição, a Constituição atual" (grifo do original).

A jurisprudência do Supremo Tribunal Federal segue a mesma linha de hermenêutica.

No julgamento do Recurso Extraordinário $n^{\circ} 78.984$ prevaleceu o voto de Ministro Cordeiro Guerra (Relator para o acórdão) que manteve válida lei anterior à Constituição de 1967/69, a título de "aplicação do princípio da continuidade do direito".

Em seu voto de adesão o Ministro Rodrigues Alkmin pondera que "se o sistema constitucional atual não se diferencia do anterior", "parece-me que permanece o ordenamento anterior, que não contesta com o sistema atualmente adotado" (Revista Trimestral de Jurisprudência - vol. 71, p. 292 e 293).

Em outro julgado, no Recurso Extraordinário $n^{\circ} 83.833$, retorna a Corte Suprema à adoção do princípio de que "permanece válida e eficaz a lei ordinária anterior à Constituição que tenha regulado matéria de lei complementar, desde que não contratante com os seus princípios e normas ou com o seu espírito" (Revista Trimestral de Jurisprudência - vol. 77, p. 657).

Elucida o então Consultor Geral da República Saulo Ramos que "a sucessão de uma ordem constitucional por outra provoca, ne- 
cessariamente, a análise entre o direito constitucional novo e o direito ordinário anterior, cujas relações são presididas pelo princípio de recepção que torna subsistentes as normas infraconstitucionais materialmente compatíveis com a nova Constituição e revoga aquelas que não ostentem esse perfil".

E acrescenta que: "o fenômeno da recepção assegura a preservação do ordenamento jurídico infraconstitucional, existente anteriormente à vigência do novo texto constitucional.

Essa ordem normativa - anterior e inferior ao estatuto fundamental - uma vez recebida pela nova Constituição, desde que ausente qualquer conflito de natureza material, passa a ter, nela, o seu novo fundamento de validade e de eficácia" (Revista de Direito Administrativo, vol. 174, p. 208).

Dentro desse princípio, conceitual assente e consagrado, o Decreto $n^{\circ} 24.599 / 74$, foi recebido pela nova Constituição, com a qual é congruente.

$\mathrm{O}$ art. 175 da Constituição prescreve que a adoção do regime de concessão para a prestação de serviços públicos far-se-á "sempre através de licitação".

A exegese do preceito se harmoniza, contudo, com a disposição do art. 22, item XXVII, que atribui à União competência privativa para legis`ar sobre normas gerais de licitação.

A norma inscrita no artigo 175 remete, em suma, ao art. $22, n^{\circ}$ XXVII, fonte da lei especial que rege o instituto de licitação.

A lei ordinária, nessa conformidade editada, incumbe regular o procedimento licitatório a ser observado para a escolha dos colaboradores da administração pública.

A lei federal em vigor (Decreto-lei $n^{\circ}$ 2.300/86 e suas alterações) dispõe exaustivamente sobre o processo de licitação e qualifica, em dispositivos especiais, os casos de dispensa, inexigibilidade e vedação das licitaçōes (arts. 22 e $23, \S 1^{\circ}$ ).

$\mathrm{O}$ advérbio que se contém no preceito constitucional não traduz o teor absoluto que aparenta, na medida em que a lei especial singulariza casos específicos incompatíveis com a realização do certame.
Se a competição é, por lei, declarada inviável ou inexigivel, a exceção confirma a regra. A norma liberatória é parte do sistema e com ele se afeiçoa.

Entre as hipóteses legais em que a licitação é dispensável, consigna o art. 22, item $\mathrm{X}$ do Decreto-lei $n^{\circ} 2.300 / 86$, "quando a operação envolver exclusivamente pessoas jurídicas de direito público interno, ou entidades paraestatais, ou, ainda, aquelas sujeitas ao seu controle majoritário, exceto se houver empresas privadas que possam prestar ou fornecer os mesmos bens ou serviços, hipóteses em que todas ficarão sujeitas a licitação.

A ressalva constante da parte final do preceito visa a manter o princípio competitivo quando a existência de empresas privadas aptas a prestar ou fornecer o bem ou serviço, permitirá à administração obter melhor proposta como fruto da licitação.

Todavia, a exceção não se aplica - determina o parágrafo único do mesmo artigo quando estiver o fornecimento de seus bens ou serviços por pessoa de direito público interno ou da administração indireta (noção que abrange a prestação de serviço concedido) sujeito a preços fixos ou tarifas, estipulados pelo Poder Público.

Ora, no caso de concessão de serviço público, cessa a liberdade de propor condições variáveis para a prestação do serviço não somente pela competência unilateral do concedente para a fixação da tarifas, como ainda e a fortiori pela faculdade que lhe assiste de determinar e mesmo modificar unilateralmente as cláusulas regulamentares de prestação do serviço concedido.

A licitação será obrigatória entre pessoas de direito privado, não abrangidas pela dispensa legal, que terão avaliados, competitivamente, os requisitos de capacidade técnica e idoneidade financeira para a exploração do serviço.

A concessão é, em sua dinâmica, uma rela. ção jurídica regulamentar, :umprindo à lei dispor sobre o "caráter especial de seu contrato" e, especialmente, "a obrigação de manter serviço adequado" (Constituiçāo, art. 175, parágrafo único).

Nos contratos administrativos prevalece o interesse público (pressuposto da finalidade 
coletiva do objeto de contrato) sobre o interesse privado. O princípio de igualdade peculiar aos contratos de direito privado, a importar na regra da imutabilidade, salvo acordo entre as partes, cede passo ao da desigualdade ao predomínio da vontade da administração sobre a do outro contratante, permitindo-lhe modificar unilateralmente as cláusulas de serviço (regra da mutabilidade do contrato administrativo).

A mutabilidade é cláusula implícita, o que adere a outra parte, habilitando a administração a alterar a obrigação de fazer do co-contratante, dentro da escala do objeto do contrato.

A obrigação do concessionário tem um conteúdo dinâmico e flexível, dentro do âmbito e da finalidade do contrato administrativo, de formar e garantir a continuidade do serviço público e a plena satisfação do interesse público em causa.

A mutabilidade do contrato de concessão, em defesa da qualidade do serviço, marca, em suma, a supremacia do interesse público, com ressalva apenas do equilíbrio financeiro do contrato.
De todo o exposto resulta que, em caso de concessão de serviço público, o caráter negocial se resume à aceitação, pelo concessionário, das condições regulamentares do serviço e a competência da administração para fixar o preço público ou a tarifa que remunera a prestação de concessionário.

A dispensa de licitação prevista no item $X$ do art. 22 do Decreto-lei $n^{\circ} 2.300 / 86$, quando de direito público interno ou entidade da administração indireta, tem aplicação na hipótese da consulta, visto que o parágrafo único do mesmo artigo cancela a incidência da exceção a que alude a parte final do preceito.

Entendemos, pelos fundamentos assinalados, que a concessão que venha a ser atribuída ao estado do Espírito Santo ou a entidade paraestatal sob seu controle ou da qual participe para explorar o porto de Vitória, poderá ser outorgada mediante adjudicação direta, com dispensa de licitação.

Rio de Janeiro, 2 de dezembro de 1991

Caio Tácito, Advogado, Professor Emérito da UERJ. 